DOI https://doi.org/10.36059/978-966-397-181-0/234-254

\title{
THE OBJECT OF THE CRIMINAL PROCEDURE PROOF
}

\section{Rachinska I. M.}

\section{INTRODUCTION}

The Ukrainian criminal process is going through difficult, but very interesting times. Reform of criminal procedural legislation, which was marked by the adoption in 2012 of the new criminal procedure code of Ukraine and which does not stop now, requires not only reflection, but also fundamental changes in the legal consciousness of scientists, law enforcement and society as a whole. The new legal reality that is emerging in the state, in our opinion, requires a revision of many ideas about the essence of individual criminal procedural institutions that impede their effective implementation. First, this applies to criminal procedural proof, because the problems of evidentiary law occupy one of the Central places in the criminal procedural theory. However, unfortunately, the current level of their development does not take into account many of the latest legislative approaches to the procedure of criminal proceedings, in particular, with regard to: the expansion of adversarial principles; strengthening of legal guarantees of the rights, freedoms and legitimate interests of participants in criminal proceedings; the introduction of international legal standards; optimization of the system of bodies that carry out pre-trial investigation and administer justice, etc. Single conceptually new approaches to the traditional ideas of criminal procedural evidence (in particular, its methodological foundations and the order of implementation), as a rule, are ignored and do not find their continuation.

In this work, the author proposes the concept of criminal procedural proof, in which, based on the analysis of modern and previous legislation, critical research of both domestic and legislation of some foreign countries, as well as the understanding of the opinions and positions expressed in the scientific literature on many problems of evidentiary activities in criminal proceedings, formulated his own vision of proof in the criminal process of Ukraine and proposed approaches to solving a number of topical theoretical and practical problems, which arise in the implementation of criminal procedural evidentiary activities. 


\section{The concept of "object of proof" and its relation to the subject of proof}

The term "object" is usually understood as a phenomenon, object, person, which is directed to a certain activity, attention ${ }^{1}$. In philosophy, it is "what the cognitive and other activities of the subject are aimed at"2. This approach to understanding the direction of human activity is generally recognized and, in our opinion applies to criminal procedural proceedings, in particular, criminal procedural evidence, since the evidentiary activities of the subjects who carry it out also has a certain direction. Therefore, we consider it quite legitimate and necessary in the study of the essence and content of criminal procedural evidence as a system of allocation of such a category as "the object of criminal procedural evidence".

In the science and practice of criminal proceedings, the concept of "object of proof" has not been previously investigated ${ }^{3}$. The term "object of proof" was used (and is used now) to name what the evidentiary activity is aimed $\mathrm{at}^{4}$. However, such approach, in our opinion, is rather doubtful as contradicts philosophical and General theoretical legal representations concerning the nature of any activity. After all, the concepts of "object" and "object" have their own distinct essence. Therefore, the definition and clarification of the features of the relationship of these concepts is important as (a) theoretical value, because: first, will contribute to bringing criminal procedural knowledge of evidence in line with the latest achievements of philosophical science regarding the ontological and epistemological essence of evidence; secondly, the allocation of the subject without the object is not methodologically correct, because the subject is always derived, secondary to the object of knowledge), and (b) practical value (because the correct understanding of what is the object and subject of proof will contribute to the proper implementation of each subject of proof of its evidentiary activity, and as a consequence, the assertion of the actual adversarial criminal proceedings).

In the scientific literature on the relationship between the concepts of "object" and "object" has not developed a clear opinion. Based on

1 Novy tlumachny slovnik ukrainskoi movi: 42000 sliv [in 4 t.] / way.: V. V. Yaremenko, N. M. Slipushko. Kyiv: Akonit, 2008. Vol. 2: ADVISER-ABOUT IT. P. 392.

${ }^{2}$ A. Dimov. State-legal regularities (V. Theory of introduction) / boilers and land rent. A. Ryzhenkov. Elista: JSC “NCE “DZHANGAR”“, 2006. P. 109.

${ }^{3}$ V. Brintseva. New dokazuvannya problemie kriminalnomu processi: navch. posib. / V. D. Brintseva, T. M. Miroshnichenko. Harkiv: NAT. the faculty of law. it looks like. Ukraine, 1998. P. 40.

${ }^{4}$ M. Groshoviy Criminal law of Ukraine. City Of Harkiv: Right, 2013. P. 191. 
generalization of various positions it is possible to allocate two approaches to this question.

The first is that under the object as a piece of objective reality (reality), which directed cognitive activity, under the subject - specific aspects of an object, its properties and condition, which, under certain conditions and circumstances, considering the cognitive demand of the subject are the purpose of these activities. That is, in this approach, in fact, the subject and the object differ as part and whole. To illustrate this approach, the example suggested in one of the works is often used. I. Lenin, where we are talking about a faceted glass (granchak) (the object is a multifaceted glass; the object is a certain face of it $)^{5}$.

The essence of the second approach is that the subject is not an integral part of the object, but its special vision, a special problem approach to it (with respect to scientific knowledge-this is what is first hidden and what science plans to reveal with the help of this knowledge). The need for such an understanding of the relationship between the object and the object of knowledge is one of the fundamental ideas Of S. Detodology. According to P. Shchedrovitsky, the object is the object of operation, and the subject is associated with the direction of formation of knowledge, which is selected. When we have a complex object X, then applying to it this or that procedure or operation, we will get this or that object projection of this object. At the same time, we can apply a different procedure to object $X$ and obtain a different knowledge - a different object projection. In each case, this knowledge will cover only a certain layer of life and existence of the object and Express the applied procedure in a symbolic form, therefore, in the knowledge of a special type.

V. Wachstein, being a supporter of this approach and considering the correlation of these concepts in sociological research, emphasizes the possibilities and means of his knowledge, which, in his opinion, is the language of description belonging to a particular subject, and another system of distinction. In his view, the object is the thing in itself; the object is what we can know about it. Such knowledge depends on the specifics of the description language used by a particular researcher; the procedure for its creation is called the conceptualization procedure. Thus, the author concludes, the language of its description makes an object an object ${ }^{6}$.

${ }^{5}$ A. Dimov. State-legal regularities (V. Theory of introduction) / boilers and land rent. A. Ryzhenkov. Elista: JSC “NCE "DZHANGAR”“, 2006. P. 109.

${ }^{6}$ A. Dimov. State-legal regularities (V. Theory of introduction) / boilers and land rent. A. Ryzhenkov. Elista: JSC “NCE "DZHANGAR”“", 2006. P. 109. 
If we consider both approaches in terms of a methodological basis, we can assume that the first is based naturalistic representation about the object and the subject, when the knowledge about a particular object get regardless of the conditions and means of production; the basis of the second approach is to determine the activity methodological approach in which the requirement to distinguish the object as a cognitive reality and the subject as posed by the defined research means the theoretical model of this reality is fundamental. In this sense, the object is what exists, and the subject is what is formed in the process of cognitive activity depending on certain worldviews, epistemological attitudes and research tools.

Summing up in this part, we note that, in our opinion, the concepts of "object" and "object" really cannot be considered as a whole and a part. An object is a part of objective reality (that which actually exists). In Criminal procedural evidence, they can define a criminal or procedural offense (or any circumstances of a criminal or procedural offense - both committed and such that can be committed (for example, in the case of evidence regarding the election of measures in accordance with part 1 of article 177 of the criminal procedure code) - which can be directed to evidentiary activities). The object of proof (criminal or procedural offense (circumstances of their Commission)) exists independently of the proof and before its appearance.

This understanding, in our opinion, is quite legitimate. It can also be used to justify the possibility of separating the proposed systemic approach (interpretation) to criminal procedural proof, along with, for example, cognitive, activity and complex. After all, really different languages of the description (systems of distinction) which are used by these or those scientists give the chance to investigate such phenomenon as criminal procedural proofs from the different parties (from the point of view of cognitive, activity system aspects). In addition, as noted above, the system analysis of any phenomenon (including evidence) can also be carried out using different forms of description (historical, subject (morphological) and functional) and thus makes it possible to determine the various references (subject) of a particular phenomenon (object).

The object of proof is always formed by him. As G. Shchedrovitsky rightly notes in this regard, starting to study or simply "including" in the activity (in our case, in the activity of proving) some object, we take it from one or more sides. These singled out parties become "substitutes" or "representatives" of the whole multilateral object; they are fixed in the sign form of knowledge. Since it is knowledge of the objectively existing, it is always objectified by us and as such forms an "object". In special scientific analysis we always regard it as adequate to the object. That's right. But at the same time it is always necessary to remember - and in methodological 
research this position becomes the main one - that the object is not identical with the object: it is a product of human cognitive activity and is subject to special laws that do not coincide with the laws of the object itself ${ }^{7}$.

One and the same object of proof may correspond to several of its subjects. This is due to the use of one or another subject of different forms of description of an object (a great interpretation of the circumstances of the criminal or procedural violations that are predicated of different functional purpose of subjects, different challenges they face, using different means of proof).

Therefore, the object of proof is not an integral part of the object, but its special vision, a special approach to it, its certain projection, and conceptualization. This is the interpretation of certain circumstances of a criminal offense, which is based on the legal positions, knowledge, and experience of a certain subject. That is, the subject of proof of certain subjects is their positional interpretation of certain circumstances of a criminal or procedural offense (the object of proof). This explains the fact that in a particular criminal proceeding with respect to the circumstances of a criminal offense in the interests of different parties may have different interpretations. In addition, it is quite normal. After all, in this case, the adversarial nature of the parties in the criminal process is possible.

In other words, extrapolating from the previous analysis, the opinion of $\mathrm{V}$. The vakhshtein, if the subject of proof, on the basis of its own system of discernment, its description language, which is predetermined as the prescriptions of the law (for example, the performance of a particular criminal procedural functions, authority) and their own discretion, depending on his legal position (as a belief regarding the perfect criminal offense, due to some purpose and motive and such, is based on a certain evidence-based), knowledge, experience, the criminal production characterizes certain circumstances a criminal or legal offense (the object of proof), then we can state the transformation of the object of proof into its subject (or in other words the appearance of the object of proof of a certain subject). Hence, it follows quite logical conclusion that the object of proof is predetermined by the object of proof and is always formed by its subject.

As noted, the object of proof is any circumstances of a criminal or procedural offense. However, not all of them can be included in the subject of proof of a particular subject. With regard to some-the law contains a mandatory requirement of the need to prove them, others can be defined as requiring proof (inclusion in the subject of proof), independently determined by the subject.

${ }^{7}$ Loboyko L. Kriminalna-combed right: course of lectures. [view. 2 so, for change. I dopov.] / L. Loboiko. Kyiv: Istina, 2008. P. 136. 


\section{Gradation of the subject of proof and general characteristics of its types}

For a better understanding of the nature of the circumstances that are subject to proof in criminal proceedings (the subject of proof), it will be advisable to make their gradation and give a General description of their types. The criterion of such gradation of the subject of proof is the degree of generality (degree of concretization) of the circumstances of the criminal offense, which are determined depending on a certain material and legal basis in the form of provisions of the General or Special parts of the criminal law (in particular, those that define the concept of "criminal offense", elements of its composition, certain types of offenses, aggravating or mitigating circumstances, and the like). Such division (gradation) of the subject of proof is carried out on the principle of the ratio of General and separate (special) and special. According to the above criterion and the principle of separation, it is possible to distinguish the subject of proof: General, generic, special and direct (individual). Each level of concretization of certain circumstances corresponds to a certain level of generalization of the characteristics of the subject.

The General subject of proof is a set of the circumstances fixed in the law to which criminal procedural proof should be directed (the structure and content of these circumstances are regulated in Art. 91 of the criminal procedure code and in the norms of the General part of the criminal law). At first glance, the list of circumstances provided for by the CPC of Ukraine is quite definite, but all of them have only a model, indicative nature. In addition, they are all common, since: first, they are subject to proof at the stage of both pre-trial investigation and trial; secondly, they form the basis not only of the indictment, but also of the sentence, the decision (determination) on the closure of criminal proceedings; thirdly, they are subject to proof in each criminal proceeding regardless of the qualification of the committed criminal offense and specific factual circumstances. This level of generalization is important for the General arrangement drawings evidentiary purposes, as well as compliance with requirements of law the comprehensiveness and completeness of research of circumstances of criminal proceedings.

In the legal literature on the circumstances of the General subject of evidence actively debated the question of their functional purpose. Some scientists (even under the previous criminal procedural legislation) expressed the opinion that their purpose is to establish only information that indicated the fact of committing a crime by a certain person ${ }^{8}$. This conclusion was not

\footnotetext{
${ }^{8}$ Larina. M. Correlation limits of proof. Modern justice. 1979. No. 15. P. 9, 10.
} 
influenced by the fact that the law, along with aggravating circumstances, also provided for the obligation to establish mitigating factors, since, as it was believed, the latter had to be objectively investigated for conviction.

It is clear that this approach is one-sided. Perhaps that is why the legislator in the current CPC of Ukraine, trying to avoid this understanding of the functional purpose (from our point of view, it is legitimate), supplemented with article 91 of the criminal procedure code circumstances, which exclude criminal responsibility or constitute grounds for termination of criminal proceedings or for excluding criminal responsibility or punishment (paragraphs 4 and 5). Such legislative novelties, in our opinion, give grounds for the assertion that the functional purpose of the subject of criminal procedural evidence is a comprehensive, complete and impartial study of the circumstances of criminal proceedings, which both confirm and deny the existence of the main fact.

The generic subject of proof is a set of circumstances of Commission of the same or similar criminal offenses. It is defined at the level of the norms of the Special part of the criminal law, which formulate specific legal features of committed criminal offenses (object, objective side, subjective side, and subject). It is at this level of gradation of the subject of proof and developed guidelines and forensic techniques of investigation of an offense, as well as explanations of the higher courts.

The special subject of proof is a certain part of circumstances of Commission of criminal offenses which character depends on a certain production. It is determined at the level of the norms of the Special part of the criminal law, which contain specific legal features of committed criminal offenses, and the norms of art. 91 code of criminal procedure and its separate chapters regulating the procedure of the so-called special industries (especially it concerns proceedings against minors and the use of coercive measures of a medical nature, as in the current criminal procedure code, which regulates the procedure for their implementation, there are special rules lead the list of circumstances to be determined in these proceedings (articles 485 and 505 of the CCP). Despite the fact that the current code of criminal procedure of Ukraine in section VI regulates other special proceedings, it seems quite legitimate (despite the absence of articles specifically devoted to this) to allocate such items of evidence and in respect of them. The circumstances included in such items of evidence are due to the legal nature of a particular special production $)^{9}$.

In essence, the circumstances of the special subject of proof are not any special, they only detail (concretize) the requirements of the General subject.

\footnotetext{
${ }^{9}$ M. Groshoviy Criminal law of Ukraine. City Of Harkiv: Right, 2013. P. 191.
} 
This can be most clearly seen based on a comparative analysis of the content of article 91 and articles 485 and 505 of the criminal procedure code of Ukraine. In particular, the circumstance provided for in paragraph 1 part 1 of article 485 of the CPC is the concretization of paragraph 4 part 1 of article 91 of the CPC; in paragraph 3 part 1 of article 485 of the CPC is the detail of paragraphs 2 and 4 part 1 of article 91 of the CPC; in paragraphs 1 and 2 part 1 of article 505 of the CPC is a repetition with the concretization of paragraphs 1 and 2 part 1 of article 91 of the CPC (respectively), etc.

An example of the possible allocation of special items of evidence in proceedings for which the law does not contain separate rules that would regulate their content is the production based on agreements. Despite its essence and the requirements regulated by the law to the content of transactions and the procedure for their conclusion and approval, the circumstances of the special subject of proof include the following: a) provided for in part 7 of article 474 of the CPC (which may be grounds for refusal to certify the agreement); b) provided for in parts 4 and $5474 \mathrm{CPC}$ (concerning the correct understanding by the parties of the agreement of the essence of the charge, certain rights and consequences of its conclusion and approval of the transaction) ${ }^{10}$.

The direct (individual) subject of proof is a set of circumstances that must be established in a particular criminal proceeding, depending on the actual circumstances inherent in the Commission of a particular criminal offense. At this level, the requirements of the law regarding the General circumstances to be proved (article 91 of the criminal procedure code), as well as the circumstances of theft, murder and the like, so to speak, "projected" on the circumstances of a particular criminal offense, acquiring unique, individual (hence the name) figures.

The circumstances that constitute the General, generic or special subject of proof are specified and supplemented in accordance with the criminal law qualification of the offense, that is, the subject of proof in a particular criminal proceeding due to the specific features of the Commission of a criminal offense and the process of its proof is individual (direct). On this in its time drew attention L. Vladimirov, who noted that the question of what is subject to proof (quid probandium), one way or another, is solved in a separate case because the criminal law requires for the composition of the relevant crime, what circumstances are taken into account when individualizing the guilt of the defendant. So, quid probandium is a question of this or that separate criminal case which one way or another is defined in the Code. In addition, the exact definition of quid probandium occurs based

${ }^{10}$ Larina. M. Correlation limits of proof. Modern justice. 1979. No. 15. P. 9, 10. 
on substantive criminal law. Legal proceedings, as a method of research, executes the program outlined by the criminal law ${ }^{11}$. In other words, in each subject of proof in a particular criminal proceeding, so to speak, "substituted" real circumstances, and each of the subjects of proof is trying to "substitute" their constants.

Such a vision seems to be quite justified, given the understanding of the essence of proof in General (as a cognitive and design-implementation activity), and its epistemological nature, in particular, from the standpoint of the need to apply a cognitive approach).

In accordance with the requirements of the law, individual (non-final) procedural decisions taken in criminal proceedings at all its stages also have their individual subject of proof (in particular, regarding: the beginning of pre-trial investigation, notification of suspicion, application of security measures, stopping of criminal proceedings, decision of recusals, etc.). They do not require the establishment of all the circumstances specified in article 91 of the CPC, but require the installation of a certain amount of other, which, as a rule, are the grounds or conditions for making certain decisions. In the legal literature, such a direct object of proof is proposed to be called a "local object" can be distinguished:

- for the beginning of pre - trial investigation (entering of data into the Unified register of pre-trial investigations (ERDR)) - the circumstances testifying to Commission of a criminal offense (part 1 of Art. 214 of the CPC) shall be established. They must first of all confirm the presence of such elements of the criminal offense as its object and objective side (that is, the circumstance provided for in paragraph 1 of part 1 of article 91 of the CPC must be established). Information about other elements of the criminal offense is not mandatory (although, for some of them, it must be (for example, information about the subjects of crimes under articles 393 and 394 of the criminal code), that is, it must be established and provided for in paragraph 2 of part 1 of article 91 of the criminal procedure code));

- for messages to the person about suspicion - it is necessary to establish that a particular person has committed a criminal offence (it is expressly provided in the third mandatory case notification on suspicion (paragraph 3 of part 1 of article 276 of the CPC) follows from the analysis of the norms regulating the grounds of a person's detention and election

${ }^{11}$ A. Dimov. State-legal regularities (V. Theory of introduction) / boilers and land rent. A. Ryzhenkov. Elista: JSC “NCE "DZHANGAR”“, 2006. P. 109.

${ }^{12} \mathrm{~V}$. Brintseva. New dokazuvannya problemie kriminalnomu processi: navch. posib. I V. D. Brintseva, T. M. Miroshnichenko. Harkiv: NAT. the faculty of law. it looks like. Ukraine, 1998. P. 40. 
concerning it measures (part 2, article 177, part 1 of article 208 of the CCP)). This means that such circumstances must be established as: the event of a criminal offense (time, place, method and other circumstances of committing a criminal offense); the guilt of a person in committing a criminal offense; absence of the circumstances excluding criminal liability or being the basis of closing of criminal proceedings. Other circumstances specified in Art. 91 of the criminal procedure code may be established at the next stage of pretrial investigation.

The circumstances of criminal proceedings, which constitute the content of the subject of criminal procedural evidence (both General, generic, special and individual), are cross-cutting, that is, they must be established both during the pre-trial investigation and in court. However, for the adoption of individual decisions, individual circumstances may sometimes not be investigated, that is, not be the subject of criminal procedural proof (in this case, the so-called truncated subject of proof may take place). For example, the decision on closing of criminal proceedings or acquittal establishment of all circumstances of subject of proof is not required; it is enough to install only some of them, but super equivalent form. In this regard, there is a problem of so-called negative facts.

Negative facts mean the absence of any facts, events, and actions. Indeed, the elements of the subject of proof can be established in both affirmative and negative form. However, this does not give grounds to talk about any special proof of negative facts. The law does require that the circumstances included in the subject of proof be established, but in what form this will be done - affirmative or negative-is a matter of specific criminal proceedings.

However, the establishment of the absence of certain elements of the subject of proof may lead to certain legal consequences, for example, to the closure of criminal proceedings. The object of proof in such cases has a truncated form, all its elements are not proved, but only a part; the need for proving others disappears. By the way, the circumstances (elements) of the subject of proof are placed in the law in such a sequence that nonconfirmation of the first automatically eliminates the need to study the following. If it is established that there was no criminal offense, it is unnecessary to look for the guilty person; if the innocence of the person is established, there is no need to establish mitigating or aggravating circumstances, etc.

Another problem that concerns the subject of proof (the circumstances of a criminal offense) and which for many years has caused quite sharp discussions among processualists is the problem of the so-called evidentiary (intermediate), auxiliary and main facts. 
By evidentiary (intermediate) are understood facts that in themselves do not have legal value, but serve only to establish other, final facts that have such a value. These, in particular, include: the facts of hostile relations between the suspect and the victim, the threat of violence, the discovery of stolen items from the suspect, the presence at the scene of a criminal offense traces left by the suspect, the presence or absence of an alibi. Evidentiary (intermediate) facts can be used both to confirm a suspicion (accusation) and to refute it. The specificity of evidentiary (intermediate) facts, which fundamentally distinguishes them from the circumstances to be proved (that is, included in the General subject of proof), is that they: (a) do not have and should not have a normative consolidation, since (b) are neither common nor the same for all criminal proceedings, but are specific for each production for a specific criminal offense ${ }^{13}$. Despite this, evidentiary (intermediate) facts are subject to proof, since by virtue of their connection with the circumstances provided for by the law as such, they must be proved, and they act as its evidence. Thus, as rightly pointed out by Y. Boronenkov, final and intermediate facts are related as ends and means of its achievement. At the same time, situations are not excluded when certain circumstances act simultaneously in one and in another capacity, since certain elements of the subject of proof, being established, can be used to prove others (for example, the method of committing a criminal offense may indicate the presence of a suspect's intent).

In connection with the above differences between the circumstances provided by the law for proof and evidentiary (intermediate) facts in the legal literature, the opinion is expressed about both the impossibility and the need to include the latter to the subject of proof. There are also proposals for the introduction of such a new category in the legal treatment as "the object of knowledge" (in our understanding "the object of knowledge"), which should include both the circumstances included in the subject of proof and evidentiary facts ${ }^{14}$.

Next to the evidentiary (intermediate) in the theory, there are also auxiliary facts, which are usually understood as circumstances that are means of identifying and verifying other circumstances (including evidentiary (intermediate) facts). These circumstances are also important for criminal proceedings, and themselves must be proved. To subsidiary facts are circumstances showing the procedure of a separate investigative (search) actions (e.g., the testimony of individuals involved in the inspection as witnesses about where they were during the conduct of investigative (search)

${ }^{13}$ Larina. M. Correlation limits of proof. Modern justice. 1979. No. 15. P. 9, 10.

${ }^{14}$ Larina. M. Correlation limits of proof. Modern justice. 1979. No. 15. P. 9, 10. 
actions), the ownership of the entity engaged to conduct a specific action (for example, about the qualifications of the specialist or expert) and the like.

Another important point on which it is advisable to stop when analyzing the subject of criminal procedural evidence is the problem of the so-called main fact. In the legal literature, opinions are expressed about the objections to the allocation and in General the need for the existence of the concept of "main fact". Proponents of this position believe that all the circumstances included in the subject of proof, in fact, are considered the main, which are equally subject to proof. The division of the circumstances that are to be proved into the main and other facts does not benefit either the theory or the practice of criminal proceedings and is superfluous. In addition, if we accept the "main fact", we can assume that there are facts and "non-main", which do not require careful installation.

This approach seems to be erroneous, because (as already noted) the circumstances included in the subject of proof (it is precisely the General subject of criminal procedural proof) are not equivalent, because among them there are determining and secondary. However, this does not mean that the latter should not be fully and comprehensively established. In support of this position, we cite the opinion Of N. Deev, who believes that to understand the role and place of the main fact in the subject of proof can help categories of content and essence. As you know, the content of any phenomenon consists not only of the main (essence), but also from the nonmain, secondary. So same to subject evidence along with the main fact (essence) includes and other circumstances. However, only their unity constitutes the entire content of the subject of proof. Note: it is not about the greater value of circumstances that are included in the main fact and not about the inferiority of circumstances that are not included in the main fact. It is a question of the priority of circumstances, which are included in the main fact, that they are "first among equals".

Moreover, we believe that the main essential reason for denying the need to highlight the main fact is the understanding by supporters of this approach of proof as a cognitive activity aimed at a full, comprehensive and objective establishment of all the circumstances of criminal proceedings and rejection of the understanding of proof as a design and implementation activity (in particular, the ability to justify their own legal position by the subject of proof (primarily with respect to the circumstances included in the main fact $)^{15}$.

15 Criminal process of Ukraine: pidruchnik / [air. M. Penny, W. It. Today, A. R. Tumanyants you in.]; land rent. Deputy: V. Today. That., Penny Air. M., Not Kaplino. V., Not Awl. City Of Harkiv : Right, 2013. P. 193. 
There is a lack of consensus among proponents of the need to single out this concept as to its content. The main fact is usually understood as a set of the most important circumstances to be proved. Among legal scholars, there are numerous more or less broad interpretations of this concept. Some scientists under the main fact understand all (or almost all) elements of the subject of proof (the circumstances of the General object of proof), in contrast to the evidentiary facts, others define it as the presence of the corpus delict in all its four elements "the object, the objective side, the subjective side and the subject". There is little in fact different from such an interpretation and definition of the main fact as a set of circumstances of the event, action (inaction) and the consequences that have occurred and which indicate the guilt of the person or her innocence.

With regard to these two approaches, it is worth noting that there is no significant difference between them, since their content is almost identical, only in the first the main fact is determined using procedural terminology, and in the second - criminal law.

Based on our own understanding of the most essential, defining, basic elements of the subject of proof, we consider it appropriate on the content of the main fact to support the point of view of Y. Orlov, who by the latter implies the fact of committing a criminal offense by a certain person,. A similar thought was expressed by V. Kurilov, who from the subject of proof (which he considered the main fact) singled out the "Central fact" the Commission of a socially dangerous act by a person, which must be proven absolutely reliably. The defining role of the main fact in this interpretation and its specificity in comparison with other elements of the proof process is that:

a) all other elements are established only in relation to the main fact. Thus, the form of guilt, the motive and purpose of committing a criminal offense, the circumstances that characterize the personality of the accused, aggravate or mitigate the punishment, shall be established only in respect of a particular person who committed a criminal offense. Without establishing the main fact of knowledge of all other circumstances loses meaning;

b) establishment of the main fact means that the criminal offense remained unsolved, and tasks of criminal proceedings unfulfilled. Failure to establish other circumstances, although it reduces the effectiveness of criminal proceedings, but does not completely exclude its effective completion, the tasks that face it. Thus, if aggravating circumstances are not proved, a person may be convicted of committing a criminal offence without aggravating circumstances;

c) the establishment of the main fact in the negative form means that there is no need to know all the other elements of the subject of proof. 
Regulatory consolidation the main facts reflected in paragraphs 1 and 2 of part 1 of article 91 of the code (where we are talking about the event of criminal offences and culpability in the Commission of the offense (note the use of the legislator that is the term "guilt", which, with our abs cover, and is committing a criminal offence by a certain person).

Summing up the above considerations, we believe that the main fact is that part of the subject of proof, which gives the latter a competitive character. Its allocation allows us to make a proposal about the need for legislative regulation of the expression by the parties at the beginning of the process of their own main thesis of proof, which will indicate the adversarial nature of the trial. For example, at the beginning of the trial, the Prosecutor notes that the person in the dock committed a certain criminal offense, which will be proved during the trial; and the defender declares that his client is innocent of committing a criminal offense, which will be proved in court.

It should also be noted that the subject of proof (this applies to such a variety of it as individual or direct), along with the material and legal facts (circumstances) also include facts of procedural importance. In particular, the consequence of non-establishment or ignoring of the facts of procedural character testifying to existence of the bases for a stop, closing of criminal proceedings, abandonment of the appeal or cassation complaint without movement or their return, etc.is acceptance of illegal or non-acceptance of the lawful decision. In such a case, the purpose of the evidence will not be fulfilled, since the court has not established the facts relevant to the criminal proceedings. Examples of other facts of procedural importance, and which are also subject to establishment in a particular criminal proceeding, are: the validity of the reason for the absence of a person who did not appear on call; the absence of circumstances precluding participation in criminal proceedings of a certain subject of criminal proceedings, etc.

\section{Limits of criminal procedural evidence}

One of the most debatable concepts in the theory of proof "limits of proof" has a significant scientific value and practical significance. In the scientific procedural literature for quite a long time, there was an opinion that "the subject of proof" and "limits of proof" are identical concepts ${ }^{16}$, which, in turn, restrained the scientific development of the latter.

Today, however, there is no doubt that these concepts are unequal, although they are close and interrelated.

${ }^{16}$ L. Glukharev. Criteria of scientific knowledge of legal two subjects. Jurisprudence. 2010. Vol. No. 2. T. 18. P. 20-28. 
In the scientific literature, there are various interpretations and interpretations of the concept of "limits of proof". So, in particular:

- some authors understand them as a set of evidence (or a certain amount of evidence), which provide the establishment of circumstances relevant to the case, the adoption of legal, reasonable and fair decisions (note that this point of view with certain variations, perhaps, is the most common);

- other scientists believe that the limits of proof should be understood not only the amount of evidence, but also the necessary investigative and judicial actions to obtain them, providing a complete, comprehensive and objective establishment of all components of the subject of proof in each particular criminal case ${ }^{17}$;

- it is also suggested that the concept of "limits of proof" covers the circumstances included in the subject of proof and evidentiary (intermediate) facts. The subject of proof reflects the category common to all cases of this category, the scope of proof is an expression of the category of a single case for each particular case [5]. Almost a similar point of view was expressed by $\mathrm{V}$. Zelenetsky, who believed that in any case it is impossible to talk about the totality of evidence, defining the concept of "limits of proof", since it is necessary to prove not the totality of evidence, but the circumstances included in the subject of proof ${ }^{18}$.

We will express our opinion on the first two approaches later. As for the third, we believe that there is a confusion of concepts "subject" and "limits of proof". Indeed, it is necessary to specify the circumstances to be proved, but here it is necessary to talk about the gradation of the subject of proof to certain levels, and not about the "limits of proof" (more about this was mentioned earlier);

- some scientists see the limits of proof in the restrictions that the law establishes for the collection, verification and evaluation of evidence at certain stages of the process (for example, in preparatory proceedings) ${ }^{19}$. With regard to the above position, we note that here we should not talk about the boundaries, but about the features of the regime of proof at different stages or in different processes, which are determined by the tasks that are solved in them. Moreover, we emphasize that in different criminal proceedings (criminal cases) at the same stage or in the same proceedings,

${ }^{17}$ M. Dieu. Pitannya kriminalnomu processi dokazuvannya in DotA mezhi drill. Ship reform in Ukraine: Matera. science.-practice. Conf. Kyiv: Yurinkom Inter, 2002. P. 262.

${ }^{18}$ Karneeva L. Attracting criminal liability. Legality of validity of the year / L. Karneeva. Moscow: Yurid. there is., 1971. P. 104.

${ }^{19}$ Kovalenko. G. New theory of criminal process in Ukraine: pid. / G. Kovalenko. Kyiv: Yurinkom Inter, 2006. P. 118. 
the limits of proof may be different and depend on the specific circumstances of certain criminal offenses;

- almost all scientists (including supporters of the above approaches) reveal the essence of the concept of "limits of proof", resorting to certain comparative illustrations. Thus, the following opinions are expressed: (a) if the object of proof is its purpose, the limits of proof-the means to achieve it; (b) if the concept of "subject of proof" means that it must be clarified, established in criminal proceedings, the concept of "limits of proof" reflects the scope and depth of the study of all significant circumstances in the proceedings; (c) if the item of evidence to be considered as the scope of the study the circumstances of the case horizontally, the limits of proof, which determine the depth of their research can be roughly defined as the frame vertically; d) the ratio of the subject and limits of proving can be represented in a coordinate system, one axis of which is the subject, and on the other the limits of proof.

- there are also views that the concept of "limits of proof" is multifaceted (multidimensional), which, in turn, predetermines the combination of different approaches. According to supporters of this position, the limits of proof are such limits of evidentiary procedural activity, which state: a) the completeness of the versions that are checked; b) the "depth" of the study of the circumstances to be established; c) the volume of evidence and their sources, mandatory for the recognition of the presence or absence of these circumstances; d) the sufficiency of substantiation of conclusions in criminal proceedings ${ }^{20}$.

Without resorting to a detailed critical analysis (neither positive nor negative) of the above approaches (some of which we have already expressed our own opinion), we believe that for a proper understanding of the concept of "limits of proof" it is necessary to distinguish between two aspects: the first-the essence of this concept and the second-the criteria for determining the moment of reaching the

With regard to the first aspect, the essence of this concept is that the limits of proof are the limits of evidentiary activity, providing a certain amount of knowledge of the subject of proof about the circumstances of the criminal offense, about which criminal proceedings are carried out, and which is sufficient for the completion of criminal procedural proof in General or for making a certain procedural decision or committing a certain procedural action, in particular. Here we are not talking about the boundaries of what is to be proved, but the boundaries of the activity that forms the content of the process of proof.

${ }^{20}$ V. Lazarev. Criminal dokazyvaet processit V.: ucheba.-practical. to posobiyami / V. A. Lazarev. Moscow: At The Height. education., 2009. P. 140. 
The second aspect of the boundaries of evidence is that to clarify the moment of achievement of the above boundaries of evidence can be used a variety of criteria, which can be separate above approaches scientists to understand the boundaries of evidence. This, in particular:

- a certain set of evidence sufficient to conclude that the study of all the circumstances of the subject of proof-here the criterion for achieving the limits of proof is a quantitative indicator of evidentiary activity. It is clear that this indicator does not and cannot have any numerical value; it is defined through the term "body of evidence". And it means that any separate proof (for example, indications about recognition by the person of the guilt) is not sufficient for a conclusion about proofs of this or that circumstance because only their set can be sufficient;

- research of all possible versions; carrying out necessary investigative (search) and judicial actions, - here again it is possible to speak about certain quantitative character of proof, however the emphasis is placed not on the received results (proofs), and on ways which lead to them;

- the degree of accuracy of knowledge about the circumstances to be proved, their reliability or probability-here the basis for determining the moment of reaching the limits of proof is assigned a qualitative indicator. Such knowledge should not contradict each other and should be in interrelation and give the chance for formulation of unambiguous conclusions. As long as there is conflicting knowledge about certain circumstances, the conclusion about their proof is doubtful, which means that the necessary limits of proof are not reached and that it is necessary to continue its implementation.

Thus, it can be stated that the "limits of proof" - the concept is quite subjective, because their definition depends on a particular subject of proof, the circumstances that need to be established in a particular criminal proceeding at a particular stage. However, a proper understanding of the nature of the boundaries of proof and the moment of their achievement is important for the characterization of the evidentiary activity of the subjects of proof. The practical importance of the study of the boundaries of proof is explained by the need to understand its subjects the importance of their correct definition. After all, groundless narrowing of these boundaries in criminal proceedings may lead to the fact that some circumstances of the subject of proof will be investigated insufficiently. Groundless expansion of borders of proof can testify to unjustified redundancy of the evidentiary information.

Another issue concerning the concept of "evidence boundaries" and requiring attention is the relationship of these boundaries at the stages of pretrial investigation and trial. Thus, $\mathrm{O}$. Larin believes that the expansion of the 
boundaries of evidence reached during the investigation is a natural and necessary condition of the trial ${ }^{21}$. However, most scientists defend the position that as the subject of proof and the requirement of the law on a comprehensive, complete and objective investigation of all the circumstances of criminal proceedings (part 2 of art. 9 CPC) are the same for both these stages, and the limits of proof are the same both in the pre-trial investigation and during the trial. However, through search, research character of procedural activity in these stages, and wrong or inaccurate definition of borders of proof, these limits in them actually can and not coincide. They can be wider at the pre-trial investigation than in court, and vice versa ${ }^{22}$.

\section{CONCLUSIONS}

1. In the study of the essence and content of criminal procedural evidence from the standpoint of a systematic approach, it is quite legitimate and necessary to allocate such a category as "the object of criminal procedural evidence".

The object of criminal procedural proof is what the evidentiary activity is aimed at, and this is a criminal or procedural offense (or any circumstances of a criminal or procedural offense - both committed and such that can be committed (for example, in the case of evidence regarding the election of measures in accordance with part 1 of article 177 of the criminal procedure code) - to which the evidentiary activity can be directed). The object of proof (criminal or procedural offense (circumstances of their Commission)) exists independently of the proof and before its appearance.

The object of proof is not an integral part of the object, but its special vision, a special approach to it, its specific projection, and conceptualization. This is the interpretation of certain circumstances of a criminal offense, which is based on the legal positions, knowledge, and experience of a certain subject. That is, the subject of proof of certain subjects is their positional interpretation of certain circumstances of a criminal or procedural offense (the object of proof). This explains the fact that in a particular criminal proceeding with respect to the circumstances of a criminal offense in the interests of different parties may have different interpretations. In addition, it is quite normal. After all, in this case, the adversarial nature of the parties in the criminal process is possible.

\footnotetext{
${ }^{21}$ Larina. M. Correlation limits of proof. Modern justice. 1979. No. 15. P. 9, 10.

${ }^{22}$ A. Luchina Subject: however based panana: monograph / Y. Lashchuk. Kiev: and palivo.V., 2011. P. 44-50.
} 
In other words, if the subject of proof, on the basis of its own system of discernment, its description language, which is predetermined as the prescriptions of the law (for example, the performance of a particular criminal procedural functions, authority) and their own discretion, depending on his legal position (as a belief regarding the perfect criminal offense, due to some purpose and motive and such, is based on a certain evidence-based), knowledge, experience, when carrying out criminal proceedings characterizes certain circumstances of a criminal or procedural offense (the object of proof), we can state the transformation of the object of proof in its subject (or in other words the appearance of the object of proof of a certain subject). Hence, it follows quite logical conclusion that the object of proof is predetermined by the object of proof and is always formed by its subject.

2. Depending on the degree of concretization of the circumstances of the criminal offense and using the principle of the ratio of General and separate (special) and special, it is possible to gradate the concept of the subject of proof into: General, generic, special and direct (individual).

3. In view of the fact that the circumstances of the General subject of proof are not equivalent, that among them there are determinants and derivatives, it is quite legitimate and expedient, both from theoretical and practical considerations, to highlight the main fact, under which it is necessary to understand the fact of committing a specific criminal offense by a certain person. Allocation of the main fact allows to suggest necessity of legislative regulation of expression by the parties at the beginning of process of own main thesis of proof that will promote expansion of competitiveness of criminal proceedings.

4. For a proper understanding of the concept of "limits of proof", we must distinguish its two aspects: the first is his essence and, second, the criteria for determining the moment of reaching the necessary evidence. The essence of this concept is that the limits of proof are the limits of evidentiary activity, providing a certain amount of knowledge of the subject of proof about the circumstances of the criminal case to be proved, and which is sufficient for the end of the criminal procedural proof in General, or for the adoption of the appropriate procedural decision or the Commission of a certain procedural action, in particular. It is not the boundary of what is to be proved (this is covered by the concept of "object of proof"), but the activity that is aimed at establishing the circumstances of the object of proof.

As for the second aspect of the boundaries of evidence highlighted by us, a variety of criteria can be used to determine the moment of achievement of the above boundaries of evidentiary activity. This, in particular: a) a certain set of evidence, which should be sufficient to conclude the study of all the circumstances of the subject of proof-here the criterion for achieving the 
limits of proof is a quantitative indicator of evidentiary activity; b) the study of all possible versions; carrying out the necessary investigative and judicial actions-here again we can talk about the quantitative nature of the evidence, but the emphasis is not on the results (evidence), but on the ways that lead to them; c) the degree of accuracy of knowledge about the circumstances to be proved, their reliability or probability-here the basis for determining the moment of reaching the limits of proof is assigned a qualitative indicator.

\section{SUMMARY}

The article deals with topical issues of the theory and practice of criminal procedural proof, which are the subject of acute discussions in the science of criminal procedure, in particular: the very essence of proof, its philosophical and methodological basis, the object and subject of proof, the purpose, motives and standards of proof, methods and means of proof, the subjects of proof and the distribution between them of the burden of its implementation.

\section{REFERENCE}

1. V. Brintseva. New dokazuvannya problemie kriminalnomu processi: navch. posib. / V. D. Brintseva, T. M. Miroshnichenko. Harkiv: NAT. the faculty of law. it looks like. Ukraine, 1998. P. 40.

2. A. Dimov. State-legal regularities (V. Theory of introduction) / boilers and land rent. A. Ryzhenkov. Elista: JSC "NCE "DZHANGAR"”, 2006. P. 109.

3. L. Glukharev. Criteria of scientific knowledge of legal two subjects. Jurisprudence. 2010. Vol. No. 2. T. 18. P. 20-28.

4. M. Groshoviy Criminal law of Ukraine. City Of Harkiv: Right, 2013. P. 191.

5. M. Dieu. Pitannya kriminalnomu processi dokazuvannya in DotA mezhi drill. Ship reform in Ukraine: Matera. Science.-practice. Conf. Kyiv: Yurinkom Inter, 2002. P. 262.

6. Karneeva L. Attracting criminal liability. Legality of validity of the year / L. Karneeva. Moscow: Yurid. There is., 1971. P. 104.

7. Kovalenko. G. New theory of criminal process in Ukraine: pid. I G. Kovalenko. Kyiv: Yurinkom Inter, 2006. P. 118.

8. Criminal process of Ukraine: pidruchnik / [air. M. Penny, W. It. Today, A. R. Tumanyants you in.]; land rent. Deputy: V. Today. That., Penny Air. M., Not Kaplino. V., Not Awl. City Of Harkiv : Right, 2013. P. 193.

9. Lazarev V. Criminal dokazyvaet processit V.: ucheba.-practical. to posobiyami / V. A. Lazarev. Moscow: At The Height. education., 2009. P. 140. 
10. Larina. M. Correlation limits of proof. Modern justice. 1979. No. 15. P. 9, 10 .

11. Loboyko L. Criminally-combed law: a course of lectures [vid. 2 so, for change. I dopov.] / L. Loboiko. Kyiv: Istina, 2008. P. 138.

12. Loboyko L. Kriminalna-combed right: course of lectures. [view. 2 so, for change. I dopov.] / L. Loboiko. Kyiv: Istina, 2008. P. 136.

13. Mikheenko M. Sovetsk proofs V. criminal proceedings: Monogr. / M. Mikheenko. Kyiv: Vishch. self., 1984. P. 106.

14. Luchina A. Subject: however based panana: monograph / Y. Lashchuk. Kiev: and palivo.V., 2011. P. 44-50;

15. Novy tlumachny slovnik ukrainskoi movi: 42000 sliv [in 4 t.] / way.: V. V. Yaremenko, No.M. Slipushko. Kyiv: Akonit, 2008. Vol. 2: ADVISER-ABOUT IT. P. 392.

Information about the author:

Rachinska I. M.,

Candidate of Law, Associate Professor, Associate Professor at the Department of Administrative,

Criminal Law and Procedure, International University of Business and Law 37-A, 49 HGD str., Kherson, 73040, Ukraine 